\title{
Hoë voorkomskoers van bakteriële vaginose en Chlamydia in 'n lae-inkomste, hoë-bevolkingsdigtheid gemeenskap in Kaapstad
}

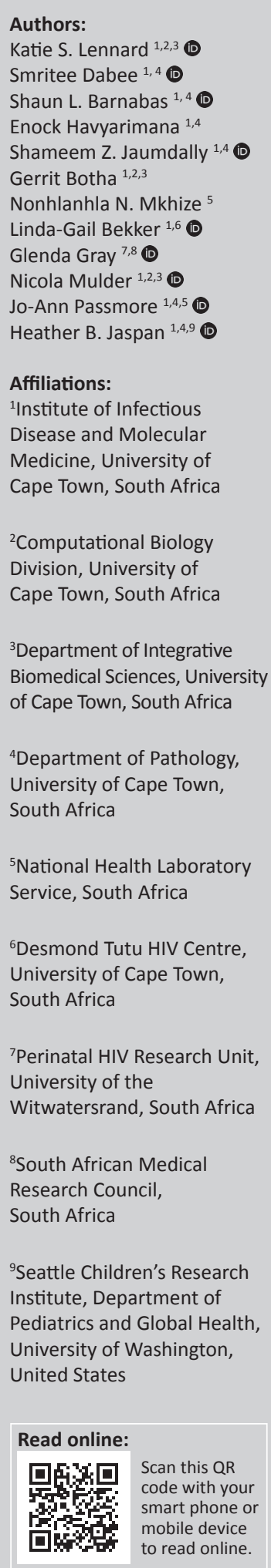

Jong Suid-Afrikaanse vroue uit hulpbron-arm gemeenskappe staar verskeie uitdagings in die gesig in terme van hulle seksuele en reproduktiewe gesondheid. Hier beskryf ons die voorkoms van vaginale mikrobiota en seksueel oordraagbare infeksies (SOI's) onder 102; 16-22-jarige MIVnegatiewe Suid-Afrikaanse vroue uit 'n lae-inkomste, hoë-bevolkingsdigtheid gemeenskap in Kaapstad. Vaginale mikrobiota is met behulp van $16 \mathrm{~S}$ rRNA amplikon volgorde-bepaling geprofileer; bakteriese vaginose (BV) status is met behulp van 'n Nugent-telling vasgestel; en SOI's is deur middel van 'n multipleks polimerase kettingreaksie bepaal. SOI's was algemeen, met $55 \%$ van die vroue wat ten minste een SOI gehad het; $41 \%$ wat met hoë-risiko menslike papillomavirus (MPV) besmet was, en 'n verdere $28 \%$ wat met laerisiko-MPV besmet was; $44 \%$ van die vroue was met Chlamydia besmet waarvan $16 \%$ een of meer addisionele SOI gehad het. BV persentasies was ook baie hoog met $55 \%$ van die vroue wat as BV-positief (Nugent-telling $\geq 7$ ) geklassifiseer is, $7 \%$ as BVintermediêr (Nugent-telling 3-6), en 38\% as BV-negatief (Nugent-telling 0-2). Streptococcus (Streptococcus agalactiae), die grootste oorsaak van neonatale sepsis, was teenwoordig in $25 \%$ van die BV-positiewe vroue en $28 \%$ van die BV-negatiewe vroue, en was dus meer onder BV-negatiewe vroue. Chlamydia-infeksie sowel as BV kan reproduktiewe gesondheid nadelig beïnvloed en verhoog hierdie vroue se risiko vir die verkryging van MIV. Die voorkoms van veral Prevotella amnii kan die MIV-risiko verhoog as gevolg van sy inflammatoriese kapasiteit. Laboratoriumgebaseerde toetsing vir SOI's (veral Chlamydia en Gonorrhoeae) blyk in hierdie gemeenskap geregverdig te wees, tesame met verdere monitering en/of behandeling van BV.

Navorsing korrelasie: Hierdie artikel is die vertaalde weergawe en is beskikbaar gestel om 'n breër lesersgroep te bereik. Die oorspronklike Engelse artikel is beskikbaar hier: https:/ / doi.org/10.4102/ satnt.v36i1.1484

High rates of bacterial vaginosis and Chlamydia in a low-income, high-population-density community in Cape Town. Young South African women, from resource-poor communities, face several sexual and reproductive health challenges. Here we describe the vaginal microbiota and sexually transmitted infection (STI) prevalence of 102; 16-22-year-old, HIV-negative South African women from a low-income, high-population-density community in Cape Town (CPT). Vaginal microbiota were profiled using 16S rRNA amplicon sequencing; bacterial vaginosis (BV) status was established using Nugent scoring; and STIs were determined by multiplex polymerase chain reaction. STIs were common, with $55 \%$ of women having at least one STI; $41 \%$ were infected with high-risk human papilloma virus (HPV) and a further 28\% with low-risk HPV; $44 \%$ were infected with Chlamydia, $16 \%$ of whom had at least one additional STI. Similarly, BV rates were very high, with $55 \%$ of women classified as BV-positive (Nugent score $\geq 7$ ); 7\% as BV-intermediate (Nugent score 3-6) and $38 \%$ as BV-negative (Nugent $0-2$ ). Group B Streptococcus (Streptococcus agalactiae), the leading cause of neonatal sepsis, was present in $25 \%$ of BV-positive women and $28 \%$ of BV-negative women, and was significantly more abundant among BV-negative women. Both Chlamydia infection and BV may adversely affect reproductive health and place these women at additional risk for HIV acquisition. The high abundance of Prevotella amnii, in particular, may increase HIV risk, given its inflammatory capacity. Laboratory-based testing for STIs (Chlamydia and Gonorrhoeae in particular) appears to be warranted in this community, together with further monitoring and/or treatment of BV.

Research correlation: This article is the translated version, made available to provide access to a larger readership, of which the original English article is available here: https://doi.org/10.4102/ satnt.v36i1.1484

Corresponding author: Katie Lennard, katieviljoen@gmail.com

Dates: Received: 09 Oct. 2017 | Accepted: 01 Nov. 2017 | Published: 12 Dec. 2017

How to cite this article: Lennard, K.S., Dabee, S., Barnabas, S.L., Havyarimana, E., Jaumdally, S.Z. \& Botha, G. et al., 2017, 'Hoë voorkomskoers van bakteriële vaginose en Chlamydia in 'n lae-inkomste, hoë-bevolkingsdigtheid gemeenskap in Kaapstad', SuidAfrikaanse Tydskrif vir Natuurwetenskap en Tegnologie 36(1), a1495. https://doi.org/10.4102/satnt.v36i1.1495

Copyright: ( 2017. The Authors. Licensee: AOSIS. This work is licensed under the Creative Commons Attribution License. 


\section{Inleiding}

Jong Suid-Afrikaanse vroue uit hulpbron-arm gemeenskappe staar verskeie uitdagings in die gesig in terme van hulle seksuele en reproduktiewe gesondheid. Die voorkomssyfer van MIV in tieners en jong vroue in Sub-Sahara Afrika is disproporsioneel hoog relatief tot hulle manlike eweknieë. Daar is verskeie faktore wat hiertoe kan bydra, insluitend die gebrek aan seksuele en reproduktiewe gesondheidsopvoeding, asook onvoldoende openbare gesondheidsdienste. Een belangrike addisionele risikofaktor vir MIV-besmetting wat klaarblyklik nie verband hou met gedrag nie, is genitale inflammasie (Masson et al. 2015). Verskeie faktore is as oorsake van genitale inflammasie voorgestel, insluitend bakteriële vaginose (BV) - gekenmerk deur verhoogde vaginale mikrobiese diversiteit en ' $n$ afname in die proporsie Lactobacilli - en seksueel oordraagbare infeksies (SOI's). Hierdie faktore blyk interafhanklik te wees, aangesien BV geassosieer word met ' $n$ verhoogde risiko van SOI-besmetting (Balkus et al. 2014; Gallo et al. 2012; Wiesenfeld et al. 2003), insluitend MIV (Atashili et al. 2008; Myer et al. 2005; Taha et al. 1998), en ook omgekeerd (Gallo et al. 2012). BV is meer algemeen in vroue van Afrika-afkoms in vergelyking met Europese vroue (Buvé et al. 2014; Ravel et al. 2010; Srinivasan et al. 2012), met 'n uiters hoë BV-voorkomssyfer in SuidAfrika (34\%-58\%) in vergelyking met ander lande (Kenyon, Colebunders \& Crucitti 2013).

Menslike papillomavirus(MPV)-infeksies hou verdere gesondheidsgevare in, aangesien hoë-risiko MPV-tipes oorsaaklik verbind is aan byna alle gevalle van servikale kanker. Servikale kanker het 'n voorkomskoers van ongeveer 30/100 000 in Sub-Sahara Afrika - vyf keer hoër as in ontwikkelde lande, soos Australië, waar MPVinenting sedert 2007 beskikbaar is (Ferlay et al. 2015). In 2000 het die Suid-Afrikaanse Nasionale Departement van Gesondheid 'n nasionale servikale kanker siftingsbeleid ingestel wat vroue ouer as 30 toegang gee tot drie gratis Papanicolaou(Pap)-smere - een elke 10 jaar (Harries et al. 2009). In 2014 het die Suid-Afrikaanse Nasionale Departement van Gesondheid MPV-profilaktiese inenting in Suid-Afrikaanse openbare skole geïmplementeer vir alle graad 4-meisies nege jaar en ouer; dit het byna ' $n$ halfmiljoen meisies geteiken.

Reproduktiewe en neonatale gesondheid verteenwoordig nog 'n groot kommer onder hierdie jong vroue, met 19\% Suid-Afrikaanse vroue wat ' $n$ tienerswangerskap (10-19 jaar oud) gehad het, waarvan 16\% ongewens was (Mchunu et al. 2012). SOI's, soos Chlamydia, kan tot pelviese inflammatoriese siekte en onvrugbaarheid lei. Die risiko van 'n ektopiese swangerskap of 'n miskraam kan ook verhoog (Anschuetz et al. 2012; Baud et al. 2011; Gottlieb, Xu \& Brunham 2013; Haggerty et al. 2010), veral as dit onbehandeld gelaat word. Verder is S. agalactiae (ook bekend as Groep B Streptococcus of GBS) die hoofoorsaak van neonatale sepsis, en indringende S. agalactiae-siekte is algemeen onder SA-babas (Madhi et al. 2003), met oordrag vanaf die moeder se genitale kanaal wat 'n groot risikofaktor vir vroeë siektes (in die eerste ses lewensdae) verteenwoordig (Edmond et al. 2012).

Hier beskryf ons die vaginale mikrobiota en voorkomskoers van SOI's onder 16-22-jarige MIV-negatiewe Suid-Afrikaanse vroue uit 'n lae-inkomste, hoë-bevolkingsdigtheid gemeenskap in Kaapstad, en beklemtoon die uitdagings wat hierdie vroue in die gesig staar in terme van hulle seksuele en reproduktiewe gesondheid.

\section{Materiaal and metodes Deelnemerseleksie en monsterversameling}

MIV-negatiewe Suid-Afrikaanse vroue tussen die ouderdomme van 16 en 22 jaar is vanuit 'n lae-inkomste, hoë-bevolkingsdigtheid gemeenskap in Kaapstad gewerf as deel van die Women's Initiative in Sexual Health studie (WISH). Alle deelnemers 18 jaar en ouer het ingeligte toestemming gegee, terwyl instemming en ouerlike toestemming vir deelnemers jonger as 18 jaar verkry is. Jong vroue is gewerf as hulle MIV-negatief was, oor die algemeen gesond was, nie swanger was of gemenstrueer het tydens die steekproefneming nie, en wat nie in die vorige $48 \mathrm{~h}$ onbeskermde seks of uitspoeling gehad het nie. Bykomende uitsluitingskriteria was die gebruik van antibiotika gedurende die voorafgaande twee weke. Vir deelnemers wat slegs progestien inspuitbare voorbehoedmiddels gebruik, is studiebesoeke geskeduleer vir twee weke ná die inspuiting, of andersins gedurende die luteale fase van hulle menstruele siklus (tussen dag 14 en 28) indien hulle geen hormonale voorbehoedmiddels (HV's) gebruik nie of indien hulle orale HV's gebruik. Voordat die monsters ingesamel is, is die volgende gedoen: MIV-voortoets en -risikoverminderingsberading, 'n vinnige MIV-toets (Alere Determine ${ }^{\mathrm{TM}} \mathrm{HIV}-1 / 2 \mathrm{Ag} / \mathrm{Ab}$ Combo, Alere, Waltham, MA), 'n swangerskaptoets (U-test Pregnancy strip, Humor Diagnostica, Pretoria, SuidAfrika), en 'n fisiese roetine-ondersoek. Genitale monsters is versamel deur 'n weggooibare menstruasiebeker (Softcup ${ }^{\circledR}$ ) vir 'n uur oor die serviks te plaas en vaginale deppers (ná bekerverwydering) te neem vir SOI-toetsing, Nugent-telling en mikrobiome-analise. Vroue is longitudinaal vir 'n totaal van drie besoeke gevolg: elke twee maande as hulle Norethisterone enanthate (Net-EN), gekombineerde mondelinge voorbehoedmiddels of slegs versperring-tipe kontrasepsie gebruik, of elke drie maande as hulle Depot medroxyprogesterone acetate (DMPA) gebruik.

\section{Seksueel oordraagbare infeksies en bakteriese vaginose toetse}

Vulvovaginale deppers is versamel vir SOI-toetsing deur multipleks polimerase-kettingreaksie (PKR) (Chlamydia trachomatis, Neisseria gonorrhoeae, Trichomonas vaginalis, Mycoplasma genitalium, HSV-1 en -2, Haemophilus ducreyi, Treponema pallidum en Lymphogranuloma venereum), soos voorheen beskryf (Lewis et al. 2012). Bloed is verkry vir die 
vinnige MIV en HSV-2 serologiese toetse. Endo-servikale deppers is ingesamel vir MPV-opsporing en genotipering deur Roche Linear Array (Mbulawa et al.) ingedien. Die volgende MPV-tipes is as hoë-risiko MPV beskou: 16, 18, 31, $33,35,39,45,51,52,56,58,59,66$ en 68 (Jacobs et al. 1997). Vir ontledings wat na SOI (enige) verwys, is vroue as positief beskou indien hulle minstens een van die SOI's (uitsluitend MPV) gehad het wat in hierdie studie getoets is. Laterale muur/posterior forniks deppers is vir die Nugent-telling ingesamel om monsters te klassifiseer as BV-negatief (Nugent 0-3), intermediêr (Nugent 4-6) of positief (Nugent 7-10); en vaginale $\mathrm{pH}$ is met behulp van kleurvaste aanwysers gemeet (Macherey-Nagel, Düren, Duitsland).

\section{Bakteriële 16S rRNS-geen multipleks polimerase-kettingreaksie amplifikasie en DNS-volgordebepaling}

Alle monsters van die eerste besoek is gekies vir 16S rRNSgeen amplifikasie deur PKR met daaropvolgende amplikonvolgordebepaling. Die deppers is ontdooi, behandel met ' $\mathrm{n}$ mengsel van 'mutanolysin' (25kU/mL, Sigma Aldrich), lisosiem (450 kU/mL, Sigma Aldrich) en 'lysostaphin' (4kU, Sigma Aldrich), en dan meganies met 'n BeadBeater ontwrig. Deoksiribonukleïensuur (DNS) is onttrek met behulp van die MoBio PowerSoil DNS-ekstraksiestel (MoBio, Carlsbad, CA). Die V4-streek van die 16S rRNS-geen is versterk deur gebruik te maak van gewysigde universele inleiers (Pearce, Hilt \& Rosenfeld 2014): 515F (TCG TCG GCA GCG TCA GAT GTG TAT AAG AGA CAG NNN NNG TGC CAG CMG CCG CGG TAA) en 806R (GTC TCG TGG GCT CGG AGA TGT GTA TAA GAG ACA GNN NNN GGA CTA CHV GGG TWT CTA AT), en die kwaliteit is met Bioanalyzer (Agilent, Santa Clara, CA, Verenigde State) nagegaan. Saamgevoegde duplikaat monsters is met AMPure XP krale (Beckman Coulter, Brea, $\mathrm{CA}$, Verenigde State) gesuiwer, en gekwantifiseer met behulp van die Picogreen dsDNA toets (Invitrogen, Carlsbad, CA, Verenigde State). Amplikone is in ekwimolêre hoeveelhede gekombineer, en gesuiwerde DNS-biblioteke bestaande uit 100 saamgevoegde monsters se gepaarde-ent volgordebepaling is uitgevoer op 'n Illumina MiSeq-platform (300bp met V3-chemie gepaarde-ent).

Ná demultipleksering is die rou DNS basisvolgordes soos volg voorverwerk: basisvolgordes vir beide rigtings (vorentoe en agtertoe) is met behulp van usearch7 (Edgar 2010) saamgevoeg, met 'n maksimum van drie onpare toegelaat; saamgevoegde basisvolgordes is gefilter volgens kwaliteit met behulp van usearch7 (basisvolgordes met E-tellings groter as 0.1 is weggegooi); inleier-sekwensies is met behulp van 'n verpersoonlikte Python teks verwyder; saamgevoegde, gefiltreerde basisvolgordes is by $250 \mathrm{bp}$ afgestomp. Hierna is sekwensies gededupliseer terwyl die vlak van replikasie vir elke ry met behulp van usearch7 aangeteken is. Die gededupliseerde sekwensies is volgens oorvloed (hoogste tot laagste) gesorteer en de novo in operasionele taksonomiese eenhede (OTE's) gegroepeer teen $97 \%$ similariteit met behulp van usearch7. Chimeriese sekwensies is met behulp van UCHIME (Edgar et al. 2011) opgespoor (in die GOLD-databasis), en verwyder. Individuele frekwensies is aan die spesifieke identifiseerders toegewys, met 'n 97\% opeenvolgingidentiteit drumpel. Taksonomiese aanwysing is uitgevoer in QIIME 1.8.0 (Caporaso et al. 2010) met behulp van die RDP-klassifiseerder (by die standaard vertrouenspeil van 0.5) teenoor die Greengenes 13.8 verwysingstaksonomie vir $97 \%$ opeenvolgingidentiteit. Om die resolusie van spesievlakke te verhoog, het ons ons verteenwoordigende de novo OTE sekwensies in die verpersoonlikte taksonomiese databasis van Fettweis et al. (2012) opgesoek, en het BLAST soektogte teen die NCBI nukleotied-databasis uitgevoer, soos voorheen beskryf.

Monsters met $\geq 5000$ basisvolgordes is vir verdere analise geselekteer. Die OTE-tabel is gestandaardiseer om verskille in totale hoeveelheid basisvolgordes tussen verskillende monsters in ag te neem, en verder gefiltreer sodat elke OTE ten minste 10 tellings in minstens $2 \%$ van die monsters moes hê of 'n relatiewe oorvloed van minstens 0.001\% moes hê.

\section{Statistiese analise}

Alle stroomaf statistiese analise is in $\mathrm{R}$ uitgevoer, met behulp van die volgende pakkette: phyloseq (McMurdie \& Holmes 2013) vir beta-diversiteitsontledings, metagenomeSeq (Paulson et al. 2013) vir differensiaal-oorvloedtoetsing, vegan (Oksanen et al. 2016) vir NMDS en RDA analise (Gaujoux 2014) vir geannoteerde hittekaarte. Verskille in mikrobiese samestelling tussen groepe van belang is geassesseer met behulp van metagenomeSeq se 'MRfulltable' funksie met 'n verpersoonlikte filter om betekenis te bepaal: saamgevoegde taksa is aansienlik anders as hulle ' $n$ veelvoud verandering (beta-koëffisiënt) van $\geq 1.25$ getoon het, 'n aangepaste $p$-waarde van $\leq 0.05$ en as minstens een van die twee groepe wat vergelyk is $\geq 20 \%$ van die monsters met die gegewe OTE/takson gehad het, of die resultaat van die Fisher eksakte toets was beduidend (ná meervoudige toetsregstellings [MT]). OTE's is eers op die laagste beskikbare taksonomiese vlak saamgevoeg (m.a.w. tellings is opgesom vir OTE's met Lactobacillus as die laagste beskikbare taksonomiese annotasie, terwyl OTE's met addisionele spesievlak annotasie, bv. L. iners, eerder op spesievlak opgesom is).

\section{Resultate}

Altesaam 149 MIV-negatiewe 16-22-jarige vroue is uit 'n lae-inkomste, hoë-bevolkingsdigtheid gemeenskap in Kaapstad gewerf. Van die 115 vroue vir wie 16S rRNS-geen amplikon-volgordebepaling uitgevoer is (a.g.v. die beskikbaarheid van deppers en voldoende DNS), het 102 die volgordebepaling se kwaliteitsbeheer geslaag (>5000 basisvolgorders/monster). Hier beskryf ons hierdie 102 vroue se mikrobiotiese profiele, SOI-voorkomssyfer en ander faktore wat van toepassing is op seksuele en reproduktiewe gesondheid (Tabel 1). 
TABEL 1: Deelnemer-opsomming $(N=102)$

\begin{tabular}{|c|c|c|}
\hline \multirow[t]{2}{*}{ Kenmerk } & \multicolumn{2}{|c|}{ Kaapstad } \\
\hline & $N$ & $\%$ \\
\hline Mediaan ouderdom & 18 & - \\
\hline \multicolumn{3}{|l|}{ BV-voorkomssyfer } \\
\hline BV-positief & 56 & 55 \\
\hline BV-intermediêr & 7 & 7 \\
\hline BV-negatief & 39 & 38 \\
\hline Nugent-telling (gemiddeld) & 5.5 & - \\
\hline SOI (enige) $\dagger$ & 56 & 55 \\
\hline Chlamydia trachomatis & 45 & 44 \\
\hline Neisseria gonorrhoeae & 14 & 14 \\
\hline Trichomonas vaginalis & 6 & 6 \\
\hline Mycoplasma genitalium & 4 & 4 \\
\hline HSV-2 & 6 & 6 \\
\hline \multicolumn{3}{|l|}{ MPV-risiko } \\
\hline Hoog & 42 & 41 \\
\hline Laag & 29 & 28 \\
\hline Negatief & 31 & 31 \\
\hline \multicolumn{3}{|l|}{ Hormonale voorbehoedmiddel } \\
\hline DMPA & 19 & 19 \\
\hline Implanon & 8 & 8 \\
\hline Net-En & 70 & 68 \\
\hline OKP & 4 & 4 \\
\hline NuvaRing & 1 & 1 \\
\hline \multicolumn{3}{|l|}{ Etnisiteit: } \\
\hline Xhosa & 94 & 99 \\
\hline Zulu & 1 & 1 \\
\hline LMI (gemiddeld) & 25.4 & - \\
\hline $\begin{array}{l}\dagger, \text { Ander SOl's wat getoets is ( } \\
\text { van die vroue bespeur nie; MP } \\
\text { Etniese inligting was nie beskik }\end{array}$ & $\begin{array}{l}\text { pallidur } \\
\text { sifikasie } \\
\text { e vroue }\end{array}$ & \\
\hline $\begin{array}{l}\text { sOl, seksueel oordraagbare inf } \\
\text { indeks. }\end{array}$ & & \\
\hline
\end{tabular}
indeks.

Die mediaan ouderdom was 18 jaar en vroue was byna uitsluitlik van isiXhosa-herkoms (99\%). Die SOIvoorkomssyfer was uiters hoog met $55 \%$ van die vroue wat met minstens een SOI gediagnoseer is deur middel van PKR. Die meerderheid van die infeksies het bestaan uit C. trachomatis (44\%), gevolg deur N. gonorrhoeae (14\%), T. vaginalis (6\%), HSV-2 (6\%) en M. genitalium (4\%). Ander SOI's waarvoor getoets is (HSV-1, H. ducreyi, T. pallidum en L. venereum) is nie in enige van hierdie vroue aangetref nie. SOI mede-infeksies was veelvuldig: $17 \%$ van die vroue was met twee of meer SOI's besmet (Tabel 2). BV-voorkomssyfers was ook baie hoog, met $55 \%$ van die vroue wat as BV-positief (Nugent-telling $\geq 7$ ) geklassifiseer is, $7 \%$ as BV-intermediêr (Nugent-telling 3-6), en 38\% as BV-negatief (Nugent-telling $0-2)$. BV-positiewe vroue was meer geneig om Chlamydia te hê (52\% van BV-positiewe teenoor 38\% van BV-negatiewe vroue was met Chlamydia besmet), maar hierdie verhouding was nie betekenisvol nie, en daar was ook geen beduidende assosiasie met die voorkoms van een of meer SOI's of BV nie. Al 102 vroue was op HV's, met die meerderheid wat die slegs-progestien inspuitbare Net-En (68\%) of DMPA $(19 \%)$ gebruik het.

\section{Vaginale mikrobiota profilering}

Ongekontroleerde groepering van mikrobiota profiele toon 'n sterk ooreenstemming tussen verhoogde mikrobiese diversiteit deur die $16 \mathrm{~S}$ rRNA-geen amplikon-
TABEL 2: Frekwensieverdeling van seksueel oordraagbare infeksies $(N=102)$, waar $1=$ positief en $0=$ negatief, bv. $8 \%$ van vroue is met Chlamydia trachomatis sowel as Neisseria gonorrhoeae gediagnoseer.

\begin{tabular}{lccccc}
\hline $\begin{array}{l}\text { Chlamydia } \\
\text { trachomatis }\end{array}$ & $\begin{array}{c}\text { Neisseria } \\
\text { gonorrhoeae }\end{array}$ & $\begin{array}{c}\text { Trichomonas } \\
\text { vaginalis }\end{array}$ & $\begin{array}{c}\text { Mycoplasma } \\
\text { genitalium }\end{array}$ & $\begin{array}{c}\text { HSV-2 } \\
\text { Frekwensie } \\
\text { (N) }\end{array}$ \\
\hline 0 & 0 & 0 & 0 & 0 & 46 \\
0 & 0 & 0 & 0 & 1 & 2 \\
0 & 0 & 0 & 1 & 0 & 1 \\
0 & 0 & 1 & 0 & 0 & 4 \\
0 & 1 & 0 & 0 & 0 & 3 \\
1 & 1 & 1 & 0 & 0 & 1 \\
1 & 0 & 0 & 0 & 0 & 29 \\
1 & 0 & 0 & 0 & 1 & 3 \\
1 & 0 & 0 & 1 & 0 & 2 \\
1 & 0 & 1 & 0 & 0 & 1 \\
1 & 1 & 0 & 0 & 0 & 8 \\
1 & 1 & 0 & 0 & 1 & 1 \\
\hline & 1 & 0 & 1 & 0 & 1 \\
\hline
\end{tabular}

volgordebepaling en BV-status (Figuur 1). Onder die BVnegatiewe vroue was $L$. iners of $L$. crispatus verreweg die volopste taksa, met aansienlik minder diverse vaginale mikrobiota in vergelyking met BV-positiewe (1.6e-7) of BVintermediêre ( $p=0.03$ ) vroue. BVAB1 was die volopste spesie in $32 \%$ van die BV-positiewe en BV-intermediêre vroue, gevolg deur G. vaginalis (17\%), Prevotella (16\%), Megasphaera, L. Iners (10\%) en L. crispatus (5\%) (sien Figuur 2).

Deur ons verpersoonlikte taksonomiese annotasie pyplyn te gebruik, kon ons alle Lactobacilli tot op spesievlak oplos. Die teenwoordige spesies was: L. iners, L. reuteri, L. crispatus, L. ruminis, L. coleohominis, L. jensenii, en L. delbrueckii. Prevotella is ook deur verskeie spesies verteenwoordig: 12 van die 19 Prevotella OTE's kon op spesievlak opgelos word, waarvan P. amnii, P. bivia, P. timonensis, P. disiens en P. pallens saam verantwoordelik was vir $\geq 50 \%$ van die Prevotellatellings in 68\% van die BV-positiewe en -intermediêre vroue (Figuur 2), terwyl Prevotella van onbekende spesies $\geq 50 \%$ in 'n verdere $27 \%$ van die BV-positiewe/-intermediêre vroue uitgemaak het.

Differensiaal-oorvloedtoetsing tussen BV-positiewe versus BV-negatiewe vroue lewer 41 beduidende taksa (Figuur 3). Soos verwag, was BVAB1, BVAB2, BVAB3, G. vaginalis, Megasphaera en verskeie Prevotella-spesies meer volop in BV-positiewe vroue. Lactobacilli, insluitend L. crispatus, L. reuteri, L. jensenii, L. iners en $L$. delbrueckii, was aansienlik meer volop in BV-negatiewe vroue.

Die voorkoms van Groep B Streptococcus is uit 16S rRNAgeen amplikon-volgordebepaling bepaal: $25 \%$ van BV-positiewe vroue en $28 \%$ van BV-negatiewe vroue is deur S. agalactiae gekoloniseer wat aansienlik meer volop onder BV-negatiewe vroue was (beta koëffisiënt $=1.4$, aangepaste $p$-waarde $=0.02)($ sien Figuur 4$)$.

\section{Bespreking}

Hier beskryf ons die voorkomssyfers van SOI en BV en die vaginale mikrobiota profiele van 16-22-jarige vroue uit 'n hulpbron-arm gemeenskap in K. Hierdie vroue het uiters hoë 


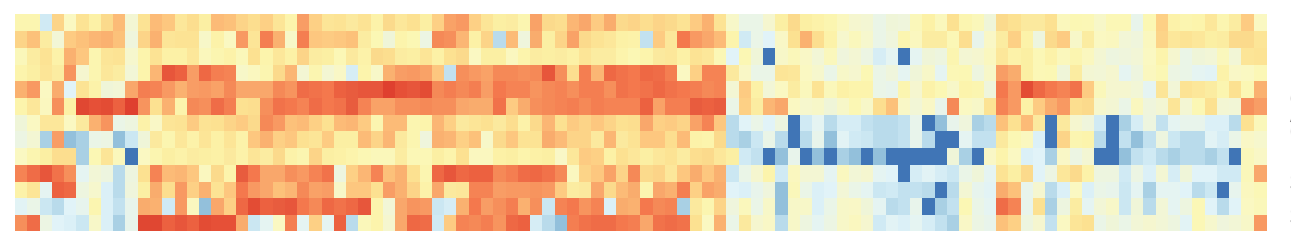

D.succinatiphilus_propionicifaciens

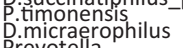

Megasphaera
G.vaginalis
Pat

A.v.
A.
C. BV

P. micra

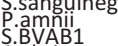

a

A.christensenii

M.a.hacchirolytica

1

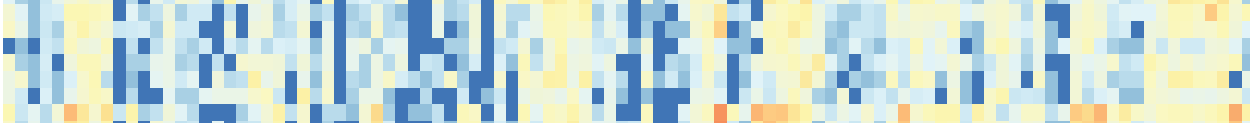

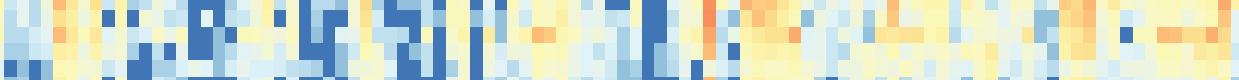

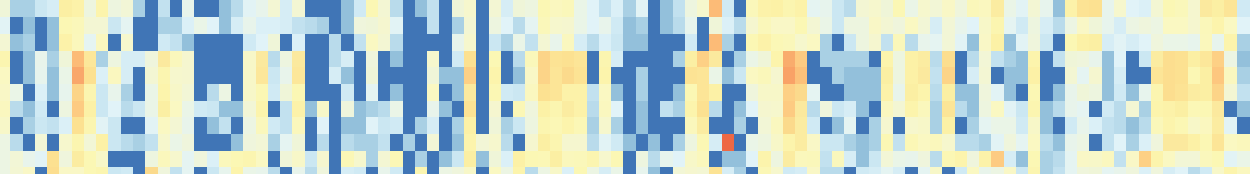

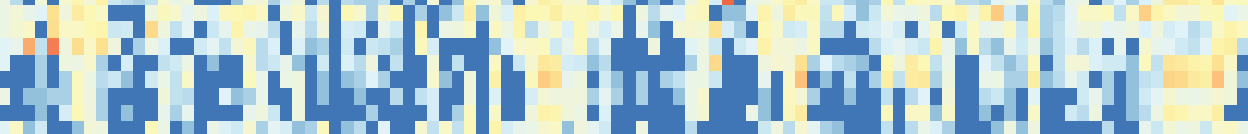

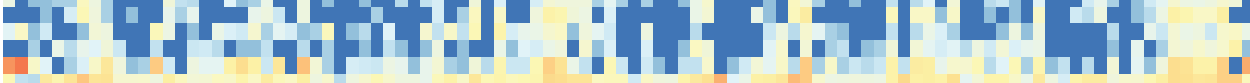

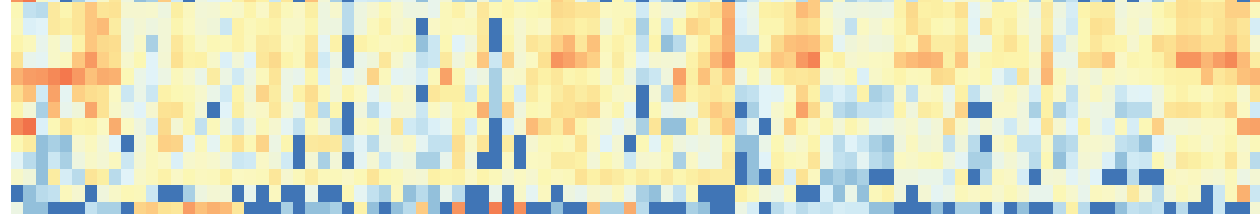

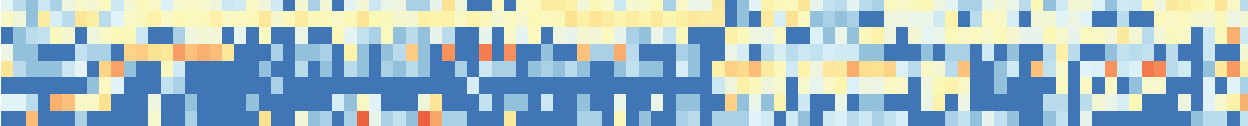

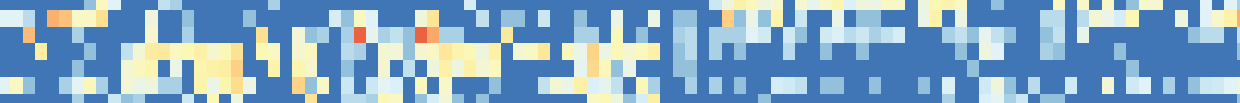

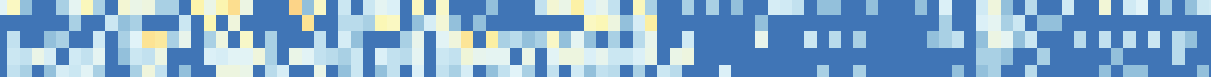

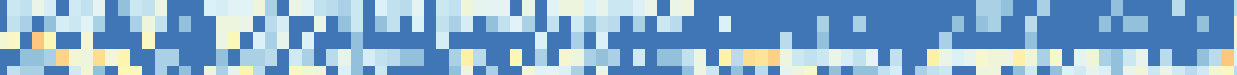

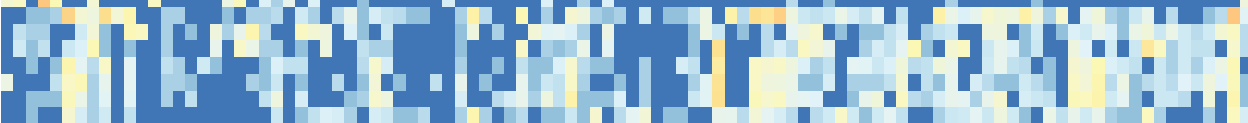
I 1 (1)

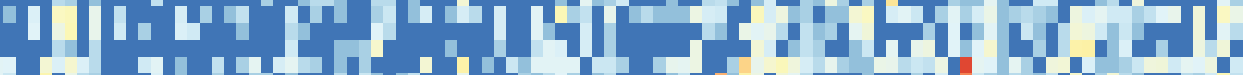

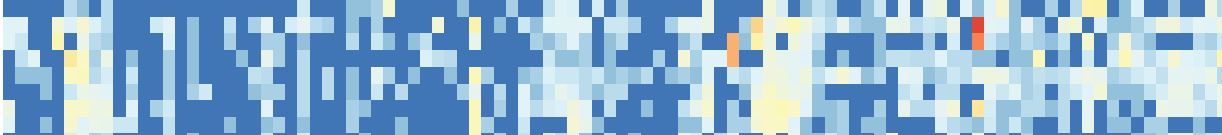
r 1.
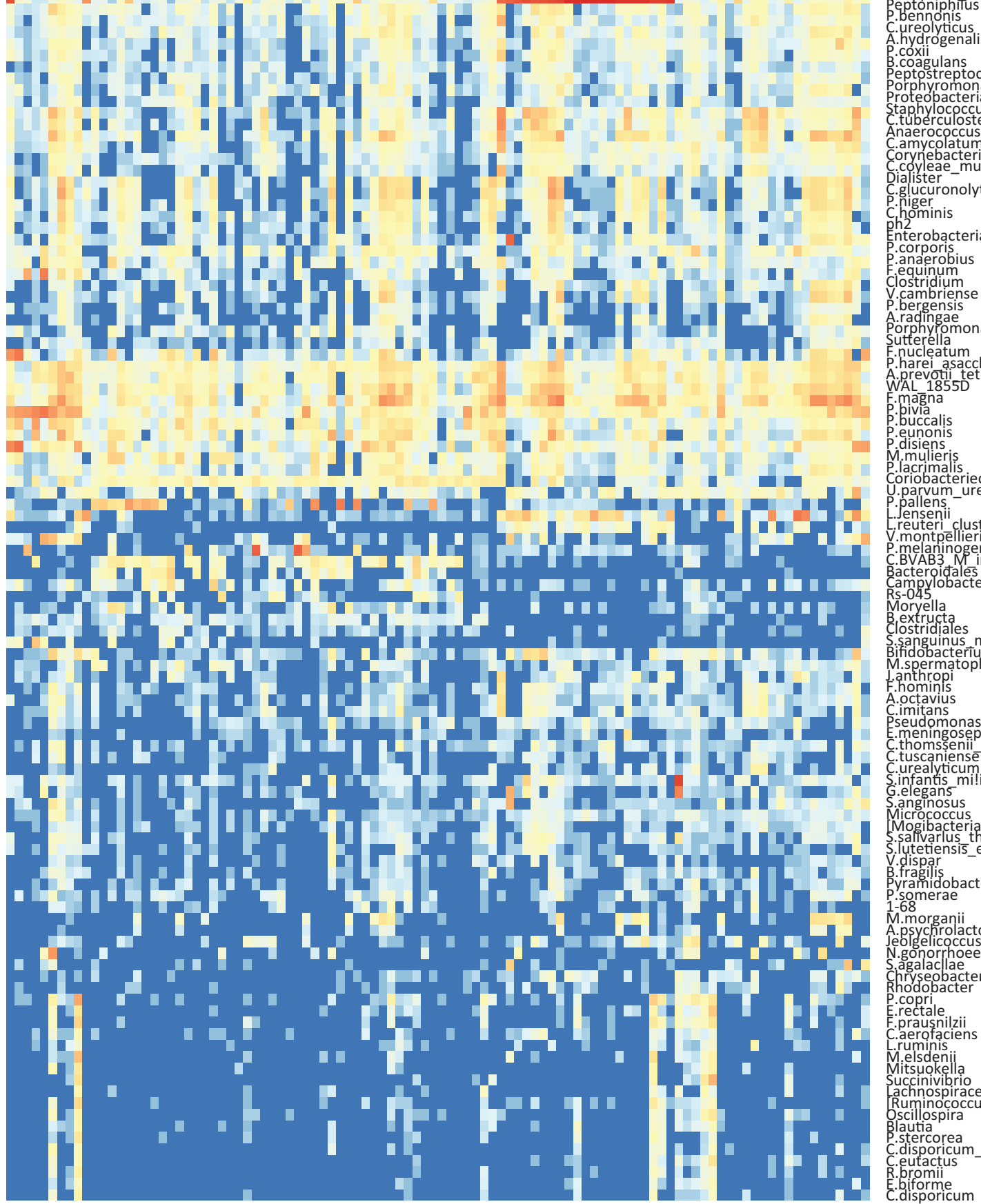

A.hydrogenalis

B.coagulans

porphyromonas

Staphylococcus
C.tuberculostearicum

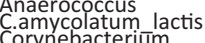

Corynebacterium
Conite

Dialister
C.glucuronolyticum

C.higer

nterobacteriaceae

p.corporis

Closuinum

P.bergensis

Porphyromonadaceae

Sutterella
F.nucleatum
h. harei asaccharolyticus grossensis A. prevotii tetradius
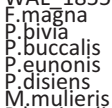

P. Iacrimalis

U.parvum urealyticum

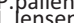

$\checkmark$. reuteri cluster

C.MVAB3 M indolicus

Cacteroidales

Moryella

sanguinus morbirenis

M.spermatophilum

F.hominis

sseudomonas

Chomssosenii sundsvallense

C.urealyticum
S.infantis milis oralis

G.elegans

Mogibacteriaceae]

S.lutetiensis_equinus

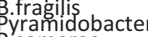

P.somerae

\section{M.morganii}

N.golgelicoccus

S.agalac lae
chryseobacterium
Rhodobacter

Rhoodobacter
P.copri

E.prausnilzii
c.aerofaciens

M.elsdenii
Mitsuokella

Succinivibrio
Lachnospiraceae

Ruminococcus)

Blautia

Cdisporicum_saudii_cela1um

FIGUUR 1: Hittekaart van die volopste taksa (rye) geïdentifiseer deur 16S rRNA-geen mikrobioomprofilering, gebruik ongekontroleerde hiërargiese klassifisering met behulp van Bray-Curtis indeks in alle monsters (kolomme). Operasionele taksonomiese eenhede (OTE's) is saamgesmelt teen die laagste beskikbare taksonomiese annotasie nadat seldsame en minder volop OTE's uitgesluit is (met 'n vereiste van ten minste 20 tellings in minstens $30 \%$ van die monsters vir ' $n$ gegewe OTE). 


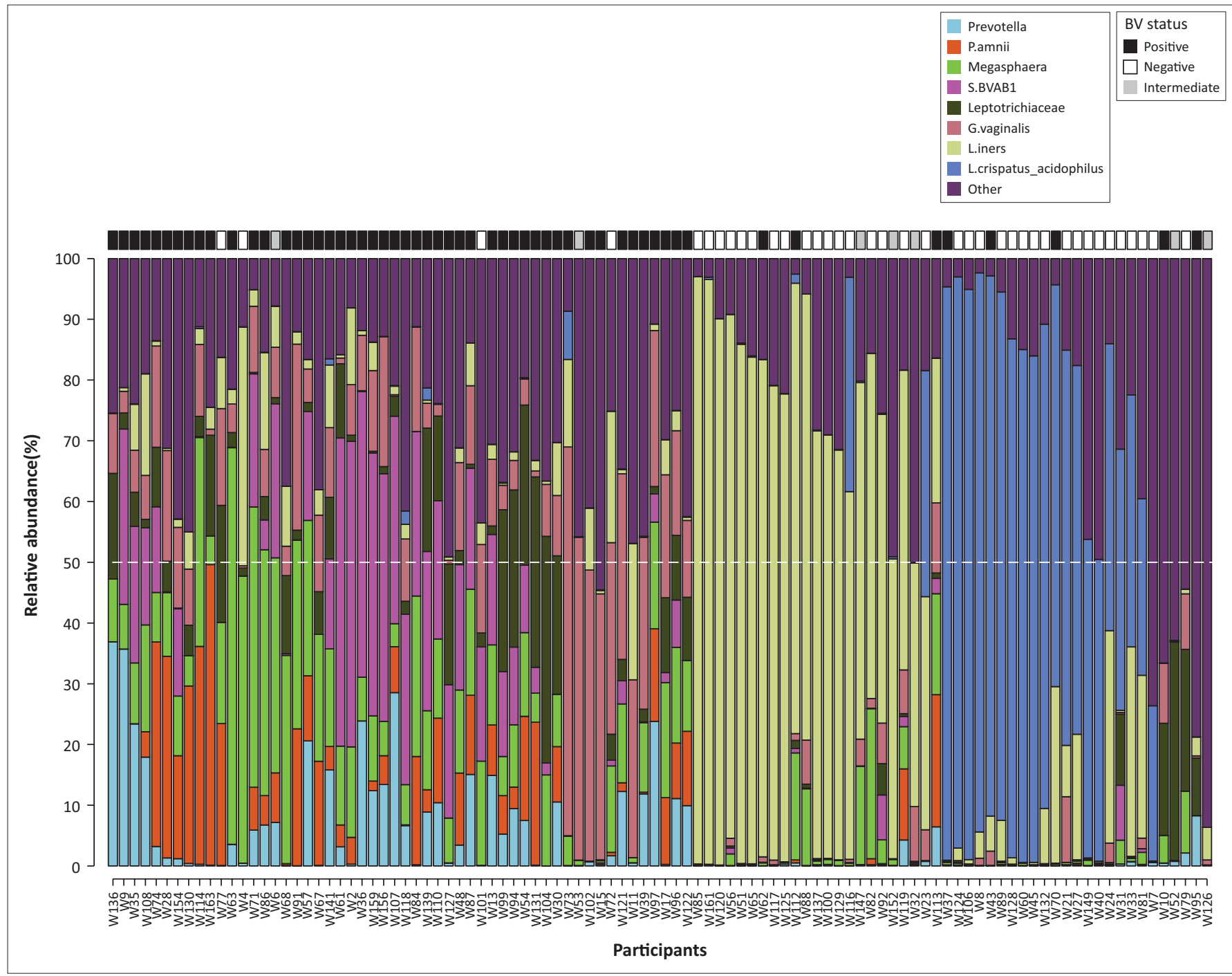

FIGUUR 2: 'n Kolomgrafiek-opsomming van die individuele mikrobiota profiele, met saamgestelde kolomme wat volgens die dominante taksa gegroepeer is en georden volgens die afnemende deel van die dominante takson. Die swart, wit en grys bokse aan die bokant dui onderskeidelik op bakteriële vaginose (BV+), BV-negatiewe en BV-intermediêre status.

SOI-voorkomssyfers (55\%). Hoë-risiko MPV is in 41\% van die vroue aangetref, met 'n verdere $28 \%$ met lae-risiko MPV. 'n Verbysterende $44 \%$ van die vroue was met Chlamydia besmet, waarvan $16 \%$ minstens een addisionele SOI gehad het. Die Chlamydia-infeksiesyfer onder hierdie vroue is aansienlik hoër as wat onder jong seksueel aktiewe vroue uit ander dele van SA gerapporteer is, insluitend die landelike streke van KwaZulu-Natal (25\%) (Kleppa et al. 2015) en 'n ander gebied in Kaapstad (15\%) (Menezes et al. 2017). Die bestuur van SOI's bly problematies in ontwikkelende lande waar laboratoriumgebaseerde toetse dikwels nie beskikbaar is nie en waar die kwaliteit van SOI-versorging tekortskiet (in terme van beskikbaarheid van medisyne, nakoming van SOI-riglyne, kondoomvoorsiening en MIV-berading [Kohler et al. 2017]). Volgens die SA Departement van Gesondheid se riglyne (Department of Health 2015), kwalifiseer vroue vir SOIbehandeling gebaseer op ' $n$ kombinasie van demografiese eienskappe, simptome en/of kliniese waarnemings, waar SOI-behandeling ' $n$ kombinasie metronidazole, azithromycin en ceftriaxone behels (Peters et al. 2014). Chlamydia is gewoonlik asimptomaties, wat die meeste vroue in SA met Chlamydia- infeksies dus onbehandeld laat. Aanhoudende Chlamydiainfeksies kan egter tot onvrugbaarheid en pelviese inflammatoriese siekte lei, asook die risiko van 'n ektopiese swangerskap en miskraam verhoog (Anschuetz et al. 2012; Baud et al. 2011; Gottlieb et al. 2013; Haggerty et al. 2010). Chlamydia word ook met 'n verhoogde risiko van MIVverkryging (Buckner et al. 2016) geassosieer wat die behoefte aan strenger SOI-sifting in hierdie gemeenskap verder beklemtoon.

BV-positiewe vroue was meer geneig om met Chlamydia besmet te wees, maar hierdie verhouding was nie betekenisvol nie, en daar was ook geen beduidende assosiasie met die voorkoms van een of meer SOI's of BV nie. Vorige verslae dui op 'n positiewe verband tussen samevallende Chlamydia/Gonorrhea en BV (Wiesenfeld et al. 2003). Hierdie assosiasie is egter nie altyd in 'n deursnee-opname duidelik nie, maar eerder longitudinaal waar insident BV geassosieer word met 'n verhoogde risiko van insident Gonorree/Chlamydia by'n opvolgbesoek, en ook omgekeerd (Gallo et al. 2012). 


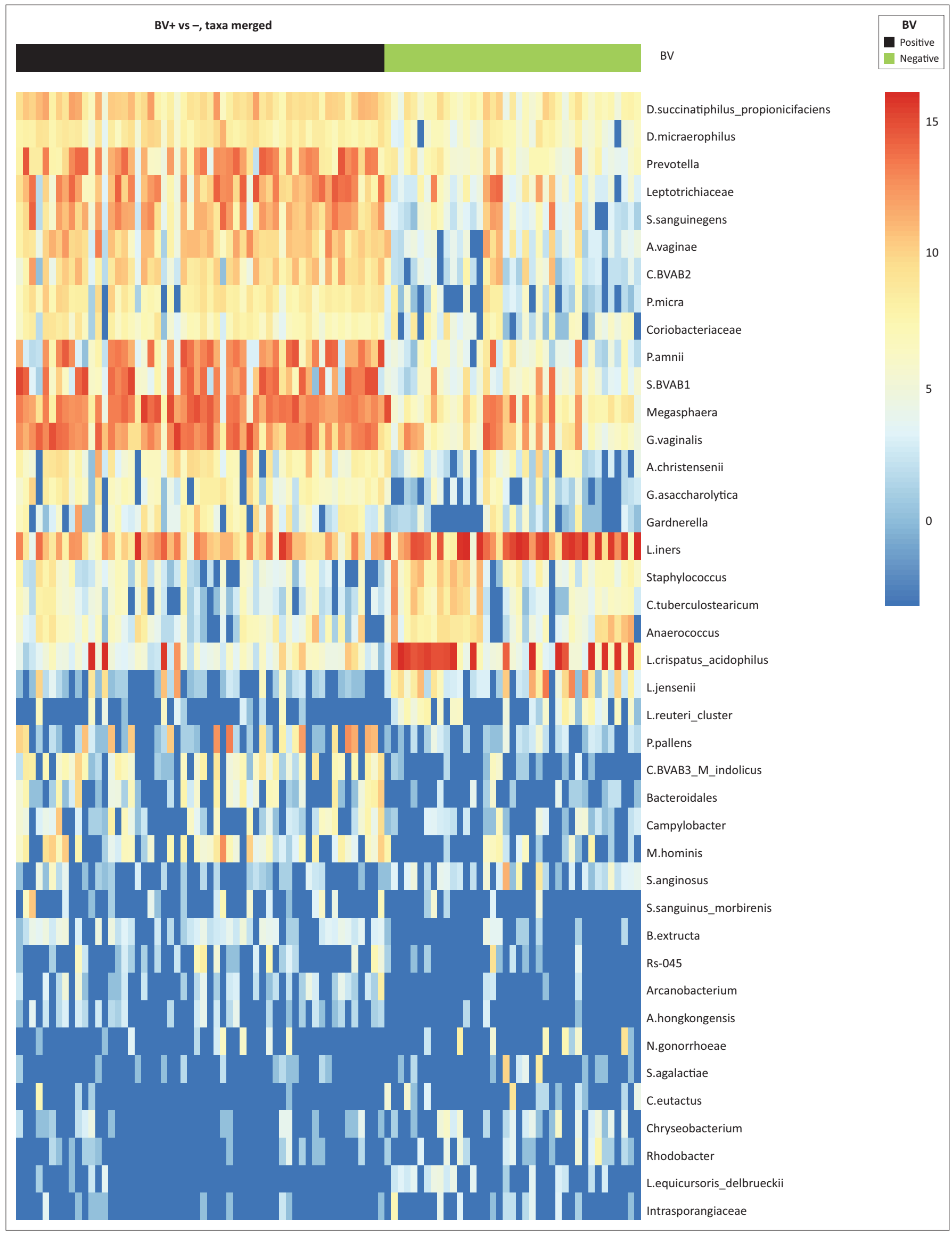

FIGUUR 3: 'n Hittekaart van taksa wat aansienlik differensieel volop en/of gereeld voorkom in BV- positiewe teenoor BV-negatiewe vroue (aangepaste $p$-waarde $\leq 0.05$, koëffisiënt $\geq 1.25$, taksa teenwoordig in $\geq 20 \%$ van die monsters in minstens een van die twee groepe wat vergelyk word); monsters (kolomme) is gesorteer volgens BVklassifikasie; hittekaartskaal: log2-getransformeerde gestandaardiseerde tellings. 


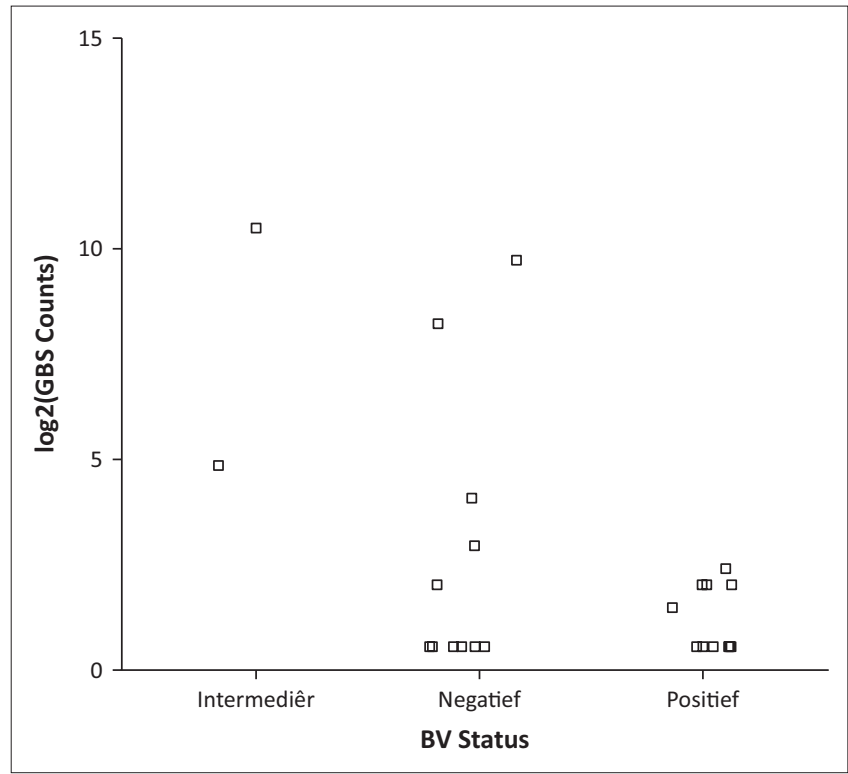

FIGUUR 4: Groep B. Streptococcus voorkoms gestratifiseer volgens BV-status.

Bakteriële vaginose voorkomssyfers in SA is oor die algemeen uiters hoog $(34 \%-58 \%)$ relatief tot ander lande (Kenyon et al. 2013). Hierdie studie het dit bevestig met $55 \%$ van die vroue wat BV-positief was. Soos in ander omgewings, het vroue met Nugent-tellings $>7$ baie uiteenlopende vaginale mikrobiota. Soortgelyk aan vorige studies oor vroue van Afrika-afkoms, het hierdie BV-positiewe vroue gereeld vaginale mikrobiota gehad, oorheers deur BVAB1, Prevotella, G. vaginalis of L. iners (Fettweis et al. 2014).

Ons was in staat om verskeie Prevotella OTE's op spesievlak op te los. P. amnii sowel as P. bivia is met genitale inflammasie (Anahtar et al. 2015; Gosmann et al. 2017; Lennard et al. 2017) en BV geassosieer. In hierdie studie het $P$. bivia-vlakke egter nie volgens BV-status of inflammasie verskil nie. Fettweis et al. (2014) het voorheen berig dat $P$. amnii meer algemeen in Afrika-Amerikaanse vroue voorkom in vergelyking met vroue van Europese afkoms wat die hoë voorkomssyfers van $P$. amnii-kolonisasie kan verduidelik wat hier gesien word. In kommersiële sekswerkers in Oos-Afrika is P. timonensis egter meer algemeen as P. amnii (Schellenberg et al. 2011). Kolonisering deur P. amnii blyk dus besonder algemeen in hierdie studiepopulasie te wees waar alle vroue deur verskillende vlakke van $P$. amnii gekoloniseer is (ongeag hulle BV-status), in vergelyking met slegs $10 \%$ en $50 \%$ van BV-negatiewe en -positiewe vroue in die studie deur Srinivasan et al. (in 'n studiebevolking waar 34\% van deelnemers swart mense was [Srinivasan et al. 2012]). Dit is egter nie duidelik of hierdie verskille toegeskryf kan word aan ras, geografiese ligging of tegniese aspekte nie.

Groep B Streptococcus (GBS) kolonisasiesyfers wissel baie dit word aangetref in $\sim 12 \%-22 \%$ van vroue in ontwikkelde en ontwikkelende lande (Stoll \& Anne 1998), met voorkomssyfers van $0 \%$ en $23 \%$ onder onderskeidelik adolessente en volwasse Suid-Afrikaanse vroue (Cools et al. 2016). Ons het geen verskil in die frekwensie van GBSkolonisasie per BV-status gevind nie. BV-negatiewe vroue gekoloniseer deur GBS het egter aansienlik hoër vlakke van GBS gehad in vergelyking met BV-positiewe vroue. Daar is voorheen getoon dat GBS-oorvloed positief geassosieer word met 'n verhoogde risiko van nadelige geboorte uitkomste. Cools et al. (2016) het bevind dat BV-negatiewe vroue meer gereeld deur GBS gekoloniseer is; Ekström et al. (2013) het 'n nie-beduidende toename in die frekwensie van GBSkolonisasie in BV-negatiewe (23.5\%) in vergelyking met BVpositiewe vroue $(17 \%)$ gerapporteer terwyl Srinivasan et al. (2012) geen verskil gevind het nie. In ons studie was nieGroep B Streptococcus S. anginosus ook aansienlik meer volop in BV-negatiewe vroue.

Ten slotte: daar is 'n hoë voorkoms van SOI's onder jong vroue tussen 16 en 22 jaar in hierdie hulpbron-arm gemeenskap in Kaapstad - veral Chlamydia en hoë-risiko MPV, sowel as BV. Chlamydia-infeksie sowel as BV kan reproduktiewe gesondheid nadelig beïnvloed en hierdie vroue teen addisionele risiko vir MIV-verkryging plaas. Die oorvloed van P. amnii in besonder kan MIV-risiko verhoog gegewe sy inflammatoriese vermoë. Laboratoriumgebaseerde toetse vir SOI's (veral Chlamydia en Gonorrhoeae) tesame met verdere monitering en/of behandeling van BV, blyk in hierdie gemeenskap geregverdig te wees.

\section{Etiese oorweging}

Goedkeuring vir die studie is vanaf die Navorsingsetiekkomitee van die Universiteit van Kaapstad verkry.

\section{Erkenning}

Ons bedank die WISH studiespanne, veral Pinky Ngobo, Nozipho Hadebe, Janine Nixon, en al die jong vroue wat aan die studie deelgeneem het. Ons bedank prof. Lynn Morris, David Lewis, Venessa Maseko en Raveshni Durgiah van die Nasionale Instituut vir Oordraagbare Siektes vir hulle hulp met steekproefverwerking. Berekeninge is uitgevoer met behulp van fasiliteite wat deur die Universiteit van Kaapstad se ICTS High Performance Computing-span voorsien is: http: / / hpc.uct.ac.za.

Hierdie studie is ondersteun deur toelaes vanaf die Europese en Ontwikkelende Lande Kliniese Proewe Vennootskap (EDCTP), Strategic Primer subsidie [SP.2011-41304.038] en die Suid-Afrikaanse Departement van Wetenskap en Tegnologie [DST/CON 0260/2012]. Katie S. Lennard word deur die Nasionale Navorsingstigting en die Suid-Afrikaanse Akademie vir Wetenskap en Kuns ondersteun. Heather B. Jaspan is gedeeltelik deur K08HD069201 ondersteun. S.L.B. is deur die HIV Vaccine Trials Network SHAPe Program, die Fogarty Foundation en die Suid-Afrikaanse Mediese Navorsingsraad (MNR) ondersteun. S.D. is deur die Nasionale Navorsingstigting van Suid-Afrika ondersteun. Die Desmond Tutu HIV Foundation erken ook die ondersteuning van ViiVgesondheidsorg in hul YouthShield-program. Perinatale MIV-navorsingseenheid is deur befondsing van die SuidAfrikaanse Mediese Navorsingsraad ondersteun. 


\section{Mededingende belange}

Die skrywers verklaar dat hulle geen finansiële of persoonlike verhouding(s) het wat hulle onvanpas beïnvloed het in die skryf van hierdie artikel nie.

\section{Outeursbydrae}

H.B.J., J.A.P., K.L. het die kohort gewerf. G.G., S.L.B., L.G.B. het die eksperimente uitgedink ontwerp. S.D., S.B., E.H., S.Z.J. het die data geanaliseer. K.L., S.D., J.A.P., G.B. het die laboratorium eksperimente uitgevoer, en K.L., J.A.P., H.B.J., S.L.B., S.D., L.G.B., E.H., N.M., N.N.M., S.Z.J., G.G., G.B. het die manuskrip geskryf.

\section{Literatuurverwysings}

Anahtar, M.N., Byrne, E.H., Doherty, K.E., Bowman, B.A., Yamamoto, H.S., Soumillon, M. et al., 2015, 'Cervicovaginal bacteria are a major modulator of host inflammatory responses in the female genital tract', Immunity 42, 965-976. https://doi.org/10.1016/j.immuni.2015.04.019

Anschuetz, G.L., Asbel, L., Spain, C.V., Salmon, M., Lewis, F., Newbern, E.C. et al., 2012 'Association between enhanced screening for Chlamydia trachomatis and Neisseria gonorrhoeae and reductions in sequelae among women', Journal of Adolescent Health 51, 80-85. https://doi.org/10.1016/j.jadohealth.2011.11.002

Atashili, J., Poole, C., Ndumbe, P.M., Adimora, A.A. \& Smith, J.S., 2008, 'Bacterial vaginosis and HIV acquisition: A meta-analysis of published studies', AIDS 22(12), 1493-1501. https://doi.org/10.1097/QAD.0b013e3283021a37

Balkus, J.E., Richardson, B.A., Rabe, L.K., Taha, T.E., Mgodi, N., Kasaro, M.P. et al., 2014 'Bacterial vaginosis and the risk of trichomonas vaginalis acquisition among HIV-1negative women', Sexually Transmitted Diseases 41, 123-128. https://doi. org/10.1097/OLQ.0000000000000075

Baud, D., Goy, G., Jaton, K., Osterheld, M.C., Blumer, S., Borel, N. et al., 2011, 'Role of Chlamydia trachomatis in miscarriage', Emerging Infectious Diseases 17, 16301635. https://doi.org/10.3201/eid1709.100865

Buckner, L.R., Amedee, A.M., Albritton, H.L., Kozlowski, P.A., Lacour, N., McGowin, C.L. et al., 2016, 'Chlamydia trachomatis infection of endocervical epithelial cells enhances early HIV transmission events', PLOS One 11, 1-20. https://doi. org/10.1371/journal.pone.0146663

Buvé, A., Jespers, V., Crucitti, T. \& Fichorova, R.N., 2014, 'The vaginal microbiota and susceptibility to HIV', Aids 28, 2333-2344. Nature Methods 7(5), 335-336. https:// susceptibility to HIV, Aids 28, 2333-2344. Nature Methods 7(5), 335-336. https://
doi.org/10.1038/nmeth.f.303 https://doi.org/10.1097/QAD.0000000000000432

Caporaso, J.G., Kuczynski, J., Stombaugh, J., Bittinger, K., Bushman, F.D., Costello, E.K. et al., 2010, 'QIIME allows analysis of high-throughput community sequencing data', Nature Methods 7, 335-336.

Cools, P., Jespers, V., Hardy, L., Crucitti, T., Delany-Moretlwe, S., Mwaura, M. et al., 2016, 'A multi-country cross-sectional study of vaginal carriage of group B streptococci (GBS) and Escherichia coli in resource-poor settings: Prevalences and risk factors', PLoS One 11, 1-30. https://doi.org/10.1371/journal.pone.0148052

Department of Health, 2015, Sexually transmitted infections management guidelines 2015, Department of Health, Republic of South Africa, pp. 4-26.

Edgar, R.C., 2010, 'Search and clustering orders of magnitude faster than BLAST', Bioinformatics 26, 2460-2461, https://doi.org/10.1093/bioinformatics/btq461

Edgar, R.C., Haas, B.J., Clemente, J.C. \& Quince, C., Knight, R., 2011, 'UCHIME improves sensitivity and speed of chimera detection', Bioinformatics 27, 2194-2200. https://doi.org/10.1093/bioinformatics/btr381

Edmond, K.M., Kortsalioudaki, C., Scott, S., Schrag, S.J., Zaidi, A.K., Cousens, S. et al., 2012, 'Group B streptococcal disease in infants aged younger than 3 months Systematic review and meta-analysis', Lancet 379, 547-556, https://doi.org/ 10.1016/S0140-6736(11)61651-6

Ekström, L., Adolfsson, A., Ericson, H., Poutakidis, G. \& Charonis, G., Larsson, P-G., 2013, 'Vaginal flora and urinary and vaginal group B streptococci in early pregnancy', Gynecology 1, 5. https://doi.org/10.7243/2052-6210-1-6

Ferlay, J., Soerjomataram, I., Dikshit, R., Eser, S., Mathers, C., Rebelo, M., Parkin, D.M et al., 2015, 'Cancer incidence and mortality worldwide: Sources, methods and major patterns in GLOBOCAN 2012', International Journal of Cancer 136, E359E386.

Fettweis, J.M., Paul Brooks, J., Serrano, M.G., Sheth, N.U., Girerd, P.H., Edwards, D.J. et al., 2014, 'Differences in vaginal microbiome in African American women versus women of European ancestry', Microbiology 160, 2272-2282.

Fettweis, J.M., Serrano, M.G., Sheth, N.U., Mayer, C.M., Glascock, A.L., Brooks, J.P. et al., 2012, 'Species-level classification of the vaginal microbiome', BMC Genomics 13, S17.

Gallo, M.F., Macaluso, M., Warner, L., Fleenor, M.E., Hook, E.W., Brill, I. et al., 2012, 'Bacterial Vaginosis, Gonorrhea, and Chlamydial Infection Among Women Attending a Sexually Transmitted Disease Clinic: A Longitudinal Analysis of Possible Causal Links', Annals of Epidemiology 22, 213-220. https://doi.org/10.1016/j. annepidem.2011.11.005
Gaujoux, R., 2014, Generating heatmaps for Nonnegative Matrix Factorization, viewed n.d., from http://nmf.r-forge.r-project.org/vignettes/heatmaps.pdf

Gosmann, C., Anahtar, M.N., Handley, S.A., Walker, B.D., Virgin, H.W., Kwon, D.S. et al., B.A., 2017, 'Lactobacillus-deficient cervicovaginal bacterial communities are associated with increased HIV acquisition in young South African women', Immunity 46, 1-9. https://doi.org/10.1016/j.immuni.2016.12.013

Gottlieb, S.L., Xu, F. \& Brunham, R.C., 2013, Screening and treating chlamydia trachomatis genital infection to prevent pelvic inflammatory disease, Sexually Transmitted Diseases 40, 1. https://doi.org/10.1097/OLQ.0b013e31827bd637

Haggerty, C.L., Gottlieb, S.L., Taylor, B.D., Low, N., Xu, F. \& Ness, R.B., 2010, 'Risk of sequelae after Chlamydia trachomatis genital infection in women', The Journal of Infectious Diseases 201, 134-155. https://doi.org/10.1086/652395

Harries, J., Moodley, J., Barone, M.A., Mall, S. \& Sinanovic, E., 2009, 'Preparing for HPV vaccination in South Africa: Key challenges and opinions', Vaccine 27, 38-44. https://doi.org/10.1016/j.vaccine.2008.10.033

Jacobs, M. V, Snijders, P.J., Helmerhorst, T.J., Meijer, J. \& Walboomers, J.M., 1997, 'A general primer GP5+ / GP6 + -mediated PCR-enzyme immunoassay method for rapid detection of 14 high-risk and 6 low-risk human papillomavirus genotyps in cervical scrapings', Journal of Clinical Microbiology 35, 791.

Kenyon, C., Colebunders, R. \& Crucitti, T., 2013, 'The global epidemiology of bacterial vaginosis: A systematic review', American Journal of Obstetrics and Gynecology vaginosis: A systematic review', American Journal of Obstetr
209, 505-523. https://doi.org/10.1016/j.ajog.2013.05.006

Kleppa, E., Holmen, S.D., Lillebø, K., Kjetland, E.F., Gundersen, S.G., Taylor, M. et al., 2015, 'Cervical ectopy: Associations with sexually transmitted infections and HIV. A cross-sectional study of high school students in rural South Africa', Sexually cross-sectional study of high school students in rural South Africa', Sexually
Transmitted Infections 91, 124-129. https://doi.org/10.1136/sextrans-2014-051674

Kohler, P.K., Marumo, E., Jed, S.L., Mema, G., Galagan, S., Tapia, K. et al., 2017, 'A national evaluation using standardised patient actors to assess STI services in public sector clinical sentinel surveillance facilities in South Africa', Sexually Transmitted Infections sextrans-2016-052930. https://doi.org/10.1136/sextrans-2016-052930

Lennard, K., Dabee, S., Barnabas, S.L., Havyarimana, E., Blakney, A., Jaumdally, S.Z. et al., 2017, 'Prevalence and associations of genital ulcer and urethral pathogens in men presenting with genital ulcer syndrome to primary health care clinics in South Africa', Sexually Transmitted Diseases 39, 880-885. https://doi. org/10.1128/IAI.00410-17

Lewis, D.A., Müller, E., Steele, L., Sternberg, M., Radebe, F., Lyall, M. et al., 2012, 'Prevalence and associations of genital ulcer and urethral pathogens in men presenting with genital ulcer syndrome to primary health care clinics in South Africa', Sexually Transmitted Diseases 39, 880-885. https://doi.org/10.1097/ OLQ.0b013e318269cf90

Madhi, S.A., Radebe, K., Crewe-Brown, H., Frasch, C.E., Arakere, G., Mokhachane, M. et al., 2003, 'High burden of invasive Streptococcus agalactiae disease in South African infants', Annals of Tropical Paediatrics 23, 15-23. https://doi.org/ 10.1179/000349803125002814

Masson, L., Passmore, J.S., Liebenberg, L.J., Werner, L., Baxter, C., Arnold, K.B. et al. 2015 , 'Genital inflammation and the risk of HIV acquisition in women', Clinical Infectious Diseases 61(2), 1-10. https://doi.org/10.1093/cid/civ298

Mchunu, G., Peltzer, K., Tutshana, B. \& Seutlwadi, L., 2012, 'Adolescent pregnancy and associated factors in South African youth', African Health Sciences 12, 426-434. https://doi.org/10.4314/ahs.v12i4.5

McMurdie, P.J. \& Holmes, S., 2013, 'Phyloseq: An R package for reproducible interactive analysis and graphics of microbiome census data', PLoS One 8, e61217. https://doi.org/10.1371/journal.pone.0061217

Menezes, L.J., Pokharel, U., Sudenga, S.L., Botha, M.H., Zeier, M., Abrahamsen, M.E. et al., 2017, 'Patterns of prevalent HPV and STI co-infections and associated factors among HIV-negative young Western Cape, South African women: The EVRI factors among HIV-negative young Western Cape, South African women: The EVRI
trial', Sexually Transmitted Infections sextrans-2016-053046. https://doi. trial', Sexually Transmitted Infectio
org/10.1136/sextrans-2016-053046

Mkhize, N.N., Bekker, L-G., Lewis, D.A., Gray, G., Mulder, N., Passmore, J-A.S. et al, 2017, 'Microbial composition predicts genital tract inflammation and persistent bacterial vaginosis in adolescent South African women', Infection and Immunity IAI.00410-17. https://doi.org/10.1128/IAI.00410-17

Myer, L., Denny, L., Telerant, R., de Souza, M., Wright, T.C. \& Kuhn, L., 2005, 'Bacterial vaginosis and susceptibility to HIV infection in South African women: A nested case-control study, Journal of Infectious Diseases 192, 1372-1380. https://doi. case-control study, Jour
org/10.1086/462427

Oksanen, A.J., Blanchet, F.G., Kindt, R., Legendre, P., Minchin, P.R., Hara, R.B.O. et al., 2016, 'Vegan: Community ecology package. R package vegan, vers. 2.2-1', World Agroforestry Centre United Nations Avenue, Gigiri.

Paulson, J.N., Stine, O.C., Bravo, H.C. \& Pop, M., 2013, 'Differential abundance analysis for microbial marker-gene surveys', Nature Methods 10, 1200-1202. https://doi. org $/ 10.1038 /$ nmeth. 2658

Pearce, M.M., Hilt, E.E. \& Rosenfeld, A.B., 2014, 'The female urinary microbiome : A comparison of women with and without urgency urinary incontinence', mBio 5(4), 1-12. https://doi.org/10.1128/mBio.01283-14

Peters, R.P.H., Dubbink, J.H., Van der Eem, L., Verweij, S.P., Bos, M.L.A., Ouburg, S. et al., 2014, 'Cross-sectional study of genital, rectal, and pharyngeal Chlamydia and Gonorrhea in women in rural South Africa', Sexually Transmitted. Diseases 41, 564-569.

Ravel, J., Gajer, P., Abdo, Z., Schneider, G.M., Koenig, S.S.K., Mcculle, S.L. et al., 2010 'Vaginal microbiome of reproductive-age women', Proceedings of the National Academy of Sciences of the United States of America (PNAS) 108, 4680-4687.

Schellenberg, J.J., Links, M.G., Hill, J.E., Dumonceaux, T.J., Kimani, J., Jaoko, W. et al., 2011, 'Molecular Definition of Vaginal Microbiota in East African Commercial Sex Workers', Applied and Environmental Microbiology 77, 4066-4074. https://doi. org/10.1128/AEM.02943-10 
Srinivasan, S., Hoffman, N.G., Morgan, M.T., Matsen, F.A., Fiedler, T.L., Hall, R.W. et al., 2012, 'Bacterial communities in women with Bacterial Vaginosis: High resolution phylogenetic analyses reveal relationships of microbiota to pone.0037818

Stoll, B.J. \& Anne, S., 1998, 'Maternal carriage of group B streptococci in developing countries', The Pediatric Infectious Disease Journal 17.6, 499-503. https://doi. org/10.1097/00006454-199806000-00013
Taha, T.E., Hoover, D.R., Dallabetta, G.A., Kumwenda, N.I., Mtimavalye, L.A, Yang, L.P. et al., 1998, 'Bacterial vaginosis and disturbances of vaginal flora: Association with increased acquisition of HIV', AIDS 12, 1699-1706. https://doi.org/10.1097/0000 2030-199813000-00019

Wiesenfeld, H.C., Hillier, S.L., Krohn, M.A., Landers, D.V. \& Sweet, R.L., 2003, 'Bacterial vaginosis is a strong predictor of Neisseria gonorrhoeae and Chlamydia trachomatis infection', Clinical Infectious Diseases 36, 663-668. https://doi.org/ $10.1086 / 367658$ 